\title{
A call to action: Moms can prevent childhood obesity
}

\section{Opinion}

Moms need to take heed to the message from Professor Donal O'Shea of Ireland's public health service who claims, "In healthcare we spend way too much on the last three months of life, and too little on the first three years of life".

As a nurse, I learned during my training decades ago that atherosclerosis, the buildup of plaque, begins from Day One with what Moms feed their newborn babies, infants and children. This plaque can clog the blood vessels leading to the heart, extremities and brain, eventually leading to strokes and heart attacks later in life. That message has motivated me to watch my diet and maintain a healthy weight for years.

What most people do not know is that plaque is made of cholesterol, fatty substances, cellular waste products and clotting materials in the blood. Cholesterol is produced by the liver from the food we ingest as babies, infants and children as we grow. However, a diet that contains excess carbohydrates, fats and sugar can influence the production of cholesterol and eventually cause the plaque buildup in blood vessels.

When plaque occurs, two things can happen. One is that a piece of plaque may break off and be carried through the bloodstream until it blocks the blood flow to the heart, brain and extremities. The other is that a blood clot (thrombus) may form on the plaque's surface that can break off and travel until it blocks smaller blood vessels. If either of these things happens, arteries can be blocked and blood flow cut off causing the death of cells/tissues that depend on daily blood flow. If the blocked artery supplies the heart or brain, a heart attack or stroke occurs. If an artery supplying oxygen to the extremities (often the legs) is blocked, gangrene can result from tissue death leading to the need for amputation of blood-deprived tissues in the extremities.

\author{
Volume 4 Issue I - 2018 \\ Thelma King Thiel \\ Liver Health Initiative, USA
}

Correspondence: Thelma King Thiel, Liver Health Initiative, Silver Spring, Maryland 20904, Tel 30I625-9076, Email livrlady@gmail.com

Received: January 26, 2018 | Published: January 29, 2018

How can Moms know if they are feeding their infants proper nutrients to avoid atherosclerosis? Watching their weight is critically important. Chubby babies are cute but may be setting off an alarm that their liver is being overwhelmed with too many sugary and fatty foods that are silently and insidiously contributing to their chubbiness and to plaque buildup in their blood vessels.

Recent research has called national attention to the fact that overweight children are most likely destined to be obese adults. More than two thirds of Americans are overweight or obese, making obesity a top national public health concern. Prevention depends a great deal on proper nutrition and lifestyle habits children learn from their caregivers. Moms need to set an example from Day One to help their children develop and maintain healthy food and lifestyle behaviors. The foundation for ensuring future health begins at home.

\section{Acknowledgments}

None.

\section{Conflict of interest}

Author declares that there is no conflict of interest. 